\title{
Conhecimentos prévios dos alunos surdos fluentes em libras referentes à linguagem algébrica no Ensino Médio
}

\author{
Silvia Teresinha Frizzarini* \\ Clélia Maria Ignatius Nogueira**
}

\section{Resumo}

Poucas são as pesquisas, com reflexões mais profundas, sobre o estudo da álgebra com alunos surdos. De forma a validar e disseminar ações educativas nesse contexto, o presente artigo tem como objetivo destacar os conhecimentos prévios dos alunos surdos, fluentes em Libras, referentes à linguagem algébrica utilizada no Ensino Médio. O embasamento teórico utilizado foi a teoria de Duval, com as análises das transformações, por tratamento e conversão dos diferentes registros de representação semiótica, em particular, das inequações. A metodologia utilizada foi a aplicação de uma avaliação diagnóstica realizada com alunos surdos, todos fluentes em Libras, de uma Escola Especial localizada no norte do Paraná. Destaca-se a necessidade de se trabalhar em ambos os sentidos de conversão, em diferentes linguagens, principalmente quando o registro de partida é o gráfico. A conclusão, a que se chegou, foi de que não se deve separar a representação algébrica dos outros registros, devido à necessidade de a língua de sinais desempenhar, não apenas função de comunicação, mas também as funções de objetivação e tratamento, fundamentais no desenvolvimento cognitivo.

Palavras-chave: Surdos fluentes em libras; Representações semióticas; Álgebra.

\footnotetext{
* Professora Doutora da Universidade Tecnológica do Paraná (UTFPR). Curitiba, Paraná, Brasil.
}

** Professora Doutora da Universidade Estadual de Maringá (UEM). Maringá, Paraná, Brasil. 


\title{
Prior knowledge of deaf students fluent in brazilian sign languages regarding the algebraic language in high school
}

\begin{abstract}
There are few researches with deeper reflections on the study of algebra with deaf students. In order to validate and disseminate educational activities in that context, this article aims at highlighting the deaf students' prior knowledge, fluent in Brazilian Sign Language, referring to the algebraic language used in high school. The theoretical framework used was Duval's theory, with analysis of the changes, by treatment and conversion, of different registers of semiotic representation, in particular inequalities. The methodology used was the application of a diagnostic evaluation performed with deaf students, all fluent in Brazilian Sign Language, in a special school located in the north of Paraná State. We emphasize the need to work in both directions of conversion, in different languages, especially when the starting record is the graphic. Therefore, the conclusion reached was that one should not separate the algebraic representation from other records, due to the need of sign language perform not only the communication function, but also the functions of objectification and treatment, fundamental in cognitive development.
\end{abstract}

Keywords: Deaf students fluent in brazilian sign language; Semiotic representations; Algebra.

\section{Introdução}

De acordo com Sacks (1998), somente a partir de meados do século XVIII, principalmente devido ao abade Clarles-Michel de L`Epée, a língua de sinais, nativa dos surdos pobres de Paris, encontrou seu uso e possibilitou uma transformação significativa que permitiu aos surdos lerem e escreverem em francês e, assim, adquirirem educação. Com a educação, o surdo deixou de ser considerado estúpido e incapaz para herdar bens, contrair matrimônio, receber instrução, ter um trabalho adequadamente estimulante, ou seja, ter os direitos humanos fundamentais. Antes dessa época, "o que se evidenciava não era nada (sic) em comparação com a destituição íntima a destituição do conhecimento e do pensamento que a surdez pré-linguística podia acarretar na ausência de qualquer comunicação" (SACKS, 1998, p. 28). Sacks afirma ainda que esse vácuo de comunicação existia devido a pessoa surda não possuir uma linguagem que a favorecesse fixar e combinar ideias.

Apesar de Clarles-Michel de L'Epée considerar, de forma equivocada por sessenta anos, a língua de sinais como um sistema de "sinais metódicos" ou "universais", destituída de gramática, deve-se entender, explica Sacks (1998, p. 34), que "[...] ela equipara-se à língua falada, prestando-se igualmente ao rigoroso e ao poético - à análise filosófica e ao namoro e, na verdade, com uma facilidade que às vezes é maior do que a da língua falada". 
O sistema de "sinais metódicos", considerado por Clarles-Michel de L'Epée, pode se equiparar a um código. Cabe aqui, então, a necessidade de diferenciar registro de código. Ambos desempenham a função de comunicação, no entanto, o código não apresenta a possibilidade de tratamento, ou seja, de transformar um elemento em outro, como a placa de trânsito ou o código Morse. Ao contrário, o termo registro, empregado inicialmente por Descartes em 1637, apresenta outras funções de objetivação e tratamento, em uma perspectiva de aquisição de conhecimento para distinguir a escrita algébrica das curvas e suas representações figurativas, o que será tratado mais à frente com o estudo dos registros, empregado por Duval (2009).

Essa história triunfante, dos surdos, continuou nos Estados Unidos até 1870, graças ao trabalho iniciado pelo reverendo norte-americano Thomas Gallaudet e pelo professor surdo francês Laurent Clerc. Entretanto, a partir de então, em consonância com o movimento geral da época - a intolerância com as minorias e suas práticas (característica do período vitoriano) -, o trabalho de um século se desfez em vinte anos. Um verdadeiro dilema que se estabelecia, crescera por décadas e existe até hoje: acreditava-se que se deveria ensinar o surdo a falar e a fazer leitura labial e, consequentemente, proibindo a comunicação por sinais, com o intuito de favorecer a integração do surdo com a população hegemônica ouvinte. O efeito foi contrário, e isso acarretou uma deterioração marcante no aproveitamento educacional das crianças surdas e em sua instrução.

No entanto, estudos linguísticos sobre as línguas de sinais, desenvolvidos após a década de 1960, particularmente por Stokoe, nos Estados Unidos, demonstraram as possibilidades cognitivas dessas línguas. No Brasil, esses estudos começam a partir da década de 1980, com FELIPE (2007) e BRITO (1995), e continuam sendo desenvolvidos, particularmente com QUADROS (1997, 2004 e 2006), QUADROS e CRUZ (2011) e KARNOPP (2004). Os denominados Estudos Surdos (SKLIAR, 1998; LOPES, 2007) possibilitaram problematizar os discursos hegemônicos sobre a surdez, na busca de transformações, no que diz respeito às representações dominantes contra as identidades surdas.

Atualmente, a Língua Brasileira de Sinais (Libras) é uma língua oficial, reconhecida pela Lei Federal n⿳o 10 436, de 2002, conhecida como a Lei da Libras, e com o Decreto 5626, datado de 2005, tornou-se obrigatório o ensino de Libras em todos os cursos de formação de professores. Essa lei é o resultado da luta dos surdos pelo reconhecimento da sua cultura; o que garantiu, no processo de educação inclusiva, a presença de um intérprete de Libras nas escolas comuns.

Mesmo assim, a inclusão educacional de surdos é repleta de controvérsias e uma delas se sustenta na intermediação da Libras em relação às especificidades existentes em cada uma das disciplinas. Essa questão reveste-se de grande importância quando a disciplina em questão é a Matemática, em função de sua característica abstrata, de difícil interpretação para uma língua essencialmente de características viso-motoras e, particularmente, por esse campo de conhecimento dispor de uma linguagem particular. 
Pode-se constatar esse fato nos trabalhos realizados, tanto em escolas bilíngues como em escolas inclusivas, por vários autores, como Goldfeld (2002); Zarfaty, Nunes e Bryant (2004); Leite, Borba e Gomes (2008); Nogueira e Zanquetta (2008). Eles reconhecem que a aprendizagem tradicional da Matemática, centrada sobre os conteúdos de ensino, não fornece aos alunos em geral, e aos surdos em particular, aptidões centradas sobre a diversidade de sistemas de representação, sobre a utilização de suas possibilidades próprias, sobre sua comparação, por colocar em correspondência e sobre suas "traduções" mútuas, uma dentro da outra, ou seja, a conversão entre distintos registros e, até mesmo a comparação entre diferentes linguagens que Duval (2009) considera fundamental.

Assim como a língua de sinais tem uma gramática própria e se apresenta estruturada em todos os níveis como as línguas orais: fonológico, morfológico, sintático e semântico, ela também tem suas características próprias em relação à linguagem matemática. No entanto, nem todas as especificidades da Matemática se relacionam diretamente com a linguagem comum e o mesmo pode-se pensar da Matemática em relação à Libras, em que uma não substitui a outra, mas ambas coexistem e estão alicerçadas no mesmo fundamento: a representação. Nesse sentido, realizou-se, neste trabalho, o entrelaçamento dessas concepções com o desenvolvimento da Libras e a linguagem algébrica. Consequentemente, um dos elementos centrais, que foi estudado nesse processo, é a linguagem algébrica do surdo fluente em Libras, educado em escola especial.

Para contextualizar com o ensino de surdos, foram identificadas as unidades constitutivas da Libras, ou seja, os sinais. Estes, em Libras, são formados, segundo Ramos, (2012), por cinco parâmetros: "configuração de mãos (CM)", "movimento (M)", "orientação das mãos (O)", "ponto de articulação (PA)" e "expressão facial/corporal (EX)" (p. 148). Quando os sinais ou unidades constitutivas, assim denominadas neste estudo, são combinados, eles formam os atos elementares de formação para cada representação.

Foram analisadas as diferentes funções discursivas da língua de sinais e o entrelaçamento dos problemas colocados pelo sistema de escrita algébrica, que Duval (2009) considera uma das linguagens formais, com os tratamentos, principalmente algorítmicos, em que "levanta dificuldades consideráveis de não congruência ${ }^{1}$ e conduz à oposição entre as línguas naturais e as línguas formais" (DUVAL, 2009, p. 23).

A não congruência é estabelecida quando não existe um dos três critérios: correspondência semântica; univocidade semântica terminal; e organização das unidades significantes. Quanto maior o número de critério que não é confirmado, de acordo com Duval (2009), a dificuldade de conversão entre registros aumenta durante a principal atividade cognitiva considerada pelo autor, a atividade de conversão. As atividades cognitivas estão vinculadas às transformações por tratamento e conversão de diferentes representações, que são:

[...]- Um tratamento é a transformação de uma representação em uma outra do mesmo registro, isto é, uma transformação estritamente interna a um registro. Existem tratamentos que são 
específicos a cada registro e que não precisam de nenhuma contribuição externa para serem feitos ou justificados. (DUVAL, 1999, apud ALMOULOUD, 2007, p. 72)

[...]- Uma conversão é a transformação de uma representação de um registro $\mathrm{D}$ em uma outra representação de um registro A, conservando, pelo menos, a referência ao mesmo objeto ou à mesma situação representada, mas mudando, de fato, o conteúdo da representação. (DUVAL, 1999, apud ALMOULOUD, 2007, p. 72)

Assim, o objetivo foi desenvolver uma avaliação diagnóstica dos principais registros de representação semiótica e suas coordenações possíveis no ensino e aprendizagem da Álgebra para alunos surdos fluentes em Libras. O conteúdo da álgebra escolhido foi a inequação, devido a sua correlação com outros conteúdos da álgebra, como função e equação.

Para a consecução deste objetivo, a metodologia utilizada foi a aplicação de uma avaliação diagnóstica dos diferentes registros de representação semiótica, assim como a identificação das correlações cognitivas entre as transformações por tratamento e conversão, segundo o referencial teórico de Duval (2009), presentes na resolução de inequações por alunos surdos fluentes em Libras.

\section{Avaliação diagnóstica}

A avaliação diagnóstica, considerada nesta investigação, constitui na aplicação de atividades aos alunos, a fim de identificar seus conhecimentos prévios sobre o assunto estudado, para que, numa futura atividade em sala de aula, pudessem ser abordados de tal forma a construir novos conhecimentos ou aprimorar os que estivessem insuficientes.

Alguns questionamentos orientaram a organização das atividades do diagnóstico, de tal modo, que o processo cognitivo, segundo Duval (2009) - a atividade de formação, tratamento e conversão -, pudesse ser identificado, perfazendo o total de cinco questões, conforme descrito a seguir:

Atividade de formação - questão 1) Os alunos surdos sabem o que é uma inequação na linguagem algébrica, geométrica e natural (Português escrito e Libras)? Os alunos reconhecem as unidades significantes das inequações apresentadas por meio de diferentes registros?

Atividade de tratamento - questões 2) e 3) Esses alunos sabem resolver uma inequação, de que forma? Sabem resolver um problema fornecido na linguagem natural envolvendo inequação?

Atividade de conversão - questões 4) e 5) Os alunos sabem associar uma inequação na linguagem natural com a representação na linguagem geométrica/gráfica e algébrica, e vice- versa?

As atividades foram realizadas em uma Escola Especial localizada no interior de uma universidade situada num município ao Norte do Estado do Paraná. Fizeram

Revista Educação Especial | v. 27 | n. 49 | p. 373-390| maio/ago. 2014

Santa Maria 
parte do diagnóstico sete alunos, fluentes em Libras, do l⿳o ano do Ensino Médio. A identidade dos alunos foi preservada, usando-se letras no lugar de seus nomes, e o uso de suas imagens foram autorizadas por seus responsáveis, para a captura dos sinais utilizados em Libras. A professora regente da turma foi voluntária desta pesquisa, o que permitiu um maior controle e exploração das atividades em Libras com os alunos surdos.

A elaboração desse diagnóstico foi subsidiada pelos trabalhos realizados por Souza (2008) - com alunos ouvintes do primeiro ano de Licenciatura Matemática e professores da rede pública - além do trabalho realizado por Duval (2009) - com alunos ouvintes do ensino básico.

As questões foram todas apresentadas na língua natural dos surdos, a Libras, juntamente com as questões escritas na sua segunda língua, o Português escrito, em respeito à diferença linguística. Foram consideradas, também as respostas, tanto as escritas em Português, quanto as comunicadas em Libras.

É importante ressaltar que a professora estabeleceu e planejou, entre os seus alunos, os próprios sinais matemáticos em Libras, às vezes com o uso de classificadores $^{2}$, em razão de esses sinais dependerem muito da questão regional, ou até mesmo da variação linguística.

As atividades foram aplicadas em quatro aulas, com duração de 50 minutos cada. Cada momento das atividades foi filmado com o auxílio de duas câmeras: uma câmera destinada à professora que traduzia, interpretava, explicava e respondia aos questionamentos dos alunos e a outra câmera destinada aos sete alunos que sinalizavam as dúvidas, respostas e discussões realizadas entre eles.

No momento das respostas em Libras, referentes à questão 5, cada aluno foi filmado separadamente, enquanto os outros esperavam sua vez de responder. As filmagens foram transcritas pela pesquisadora, com a ajuda de uma professora surda, do Departamento de Letras, da mesma universidade em que se realizou a pesquisa. Garantiu-se, assim, a captura de toda comunicação realizada em sala de aula, além das respostas escritas dos alunos.

Dos sete alunos que fizeram parte da pesquisa, apenas seis estavam presentes para realizar as questões de l a 4. Essas questões foram desenvolvidas durante dois dias seguidos, com uma aula no primeiro dia e duas aulas no segundo. A questão 5 foi desenvolvida com todos os sete alunos que participavam da pesquisa, durante um dia com duas aulas. Os materiais utilizados pelos alunos, em todas as questões, constituíram-se nas folhas de questões, lápis e borracha, e pela professora, a lousa e o data-show.

\section{Resultados obtidos}

Os resultados foram separados de acordo com a categoria de linguagem (algébrica, gráfica e discursiva, que consideramos aqui o Português escrito e a Libras) utilizada pelos seis alunos que estavam presentes nesse dia. 


\section{Questão 1 - Atividade de formação}

1. São dadas algumas expressões na linguagem algébrica, natural e gráfica. Indique para cada item qual representa: equação (E), inequação (I) ou função (F).

$$
\text { (a) } y=2 x+3
$$

(e)

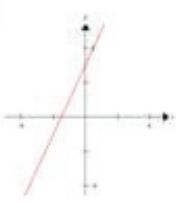

(b) $-x+1=0$

(c) $f(u)=u^{3}$

(f)

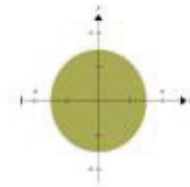

(g) Conjunto dos pontos cuja abscissa é positiva.

(h) Conjunto dos pontos cuja ordenada é igual à abscissa.

Para cada categoria de linguagem foram analisadas, segundo a teoria de Duval (2009), as unidades significantes, de modo a distinguir inequação, equação e função. Quando o registro era o gráfico, as analises foram realizadas sobre suas unidades visuais; quando o registro era o algébrico, as analises foram realizadas sobre as suas unidades simbólicas; e, quando a representação era o Português escrito e/ou a Libras, as analises foram realizadas sobre as unidades semânticas. As análises correspondiam para cada sentença matemática, seja ela uma equação, inequação ou função. As unidades significantes consideradas, para a linguagem algébrica, foram: $<,=, f(u), y=$, etc; para a linguagem gráfica foram: inclinação, interseção com os eixos, região hachurada, etc; para o Português escrito foram: valores acima ou abaixo, abscissa igual, ordenada menor que, valores maiores ou iguais, conjunto de ponto, etc; e para a Libras foram destacadas nas figuras 1,2 e 3.

Linguagem algébrica: quatro alunos identificaram as regras de formação para as inequações e equações no registro algébrico e três alunos identificaram as regras de formação para a função. Esses resultados de identificação, no registro algébrico, se justificam pela congruência entre os dois registros, linguagem algébrica e da Libras, com a correspondência entre as unidades simbólicas e as unidades semânticas, como pode ser observado nas figuras 1,2 e 3.
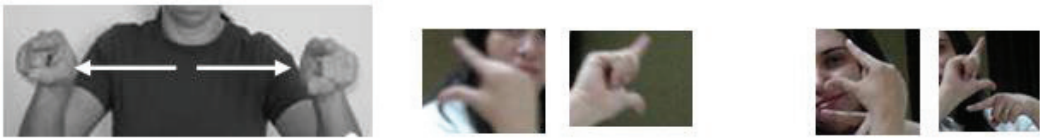

Figura 1: unidades significantes do sinal utilizado para inequações em Libras.

Fonte: arquivo dos autores 


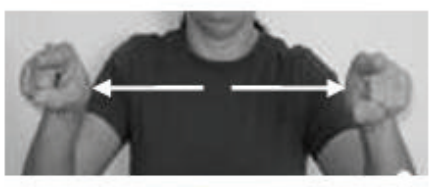

a

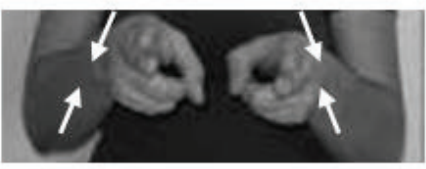

b

Figura 2: unidades significantes do sinal utilizado para equação em Libras.

Fonte: arquivo dos autores

Linguagem gráfica: Todos os alunos responderam que ambos os gráficos eram uma função. Isso se justifica pela correspondência do registro na língua de sinais e da linguagem gráfica. As unidades significantes da palavra "função", em Libras (Fig. 3), correspondem às regras elementares de formação para qualquer gráfico no plano cartesiano, seja de uma função, inequação ou equação. No entanto, para o aluno surdo, seja qual for o gráfico que estiver representado num plano cartesiano, a função é o único representante, devido ao sinal utilizado em Libras.

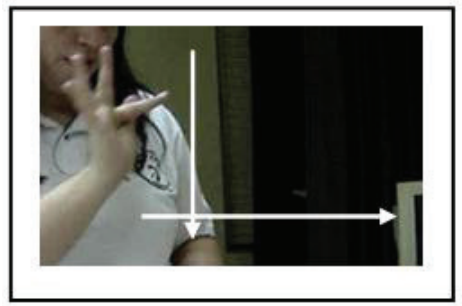

Figura 3: unidades significantes do sinal utilizado para função em Libras.

Fonte: arquivo dos autores

Português escrito: apenas dois alunos acertaram as regras de formação nesse registro para as inequações. A ausência da palavra "maior" ou "menor" e a presença da palavra "abscissa", nas sentenças, induziram os outros quatro alunos a considerarem uma inequação como sendo uma função, já que uma função é traduzida, em Libras, pelos eixos perpendiculares, assim como foram traduzidas as palavras "abscissa" e "ordenada". A presença das palavras "é igual" e "ordenadas e abscissas" traz correspondência com as unidades significantes, em Libras, do sinal de igual e do sinal de função, respectivamente.

Para Duval (2009), a identificação das regras de formação não garante a compreensão dessas representações ou de sua exploração, como será possível ver nas próximas atividades. 


\section{Questões 2 e 3 - Atividade de tratamento}

2. Resolva as inequações, explicitando qual é a incógnita. Deixe os passos de sua resolução ou explique como você chegou à solução.
$(a)-x<6$
(b) $\frac{t}{-2} \geq 4$
(c) $y^{2} \leq 2$
$5(d) 1>5 x$

3. Subtraindo 6 anos da idade de Vera Lúcia, obtém-se um número menor que 2. Qual a idade de Vera Lúcia, sabendo que ela é a maior possível?

Linguagem algébrica: o tratamento realizado no item a foi realizado apenas por um aluno, pelo princípio multiplicativo, com um número negativo, mas sem inverter o sinal de desigualdade. No item $b$, cinco alunos realizaram a "multiplicação em cruz", sem o cuidado com o sinal negativo. No item c, todos os alunos extraíram a raiz quadrada dos dois lados da desigualdade, obtendo a resposta $x<5$ ou $x< \pm 5$. No item d, quatro alunos resolveram por meio do princípio multiplicativo, de forma generalizada, ou seja, realizaram a divisão pelo coeficiente da variável no membro oposto. Nenhum aluno inverteu o sinal da desigualdade, ao inverter os dois membros da desigualdade.

Os mesmos processos de tratamento algébrico, utilizado na resolução de uma equação, são transpostos para as inequações, o que acarretou os erros. Esse fato pode ser observado tanto por alunos surdos como por ouvintes, conforme Souza (2008).

Linguagem gráfica: nenhum método gráfico foi utilizado nas questões 2 e 3. A construção de gráficos é suplantada pela proposta de um "dispositivo prático" para agilizar a resolução da inequação, como é visto no livro didático adotado pela Escola Especial (PAIVA, 2003, p. 82). Percebe-se, nesse livro, que a resolução, por meio da tabela, na linguagem numérica, é apresentada como um processo mais eficiente que a resolução na linguagem gráfica, o que justifica a influência da aritmética na resolução das operações algébricas apresentadas pelos alunos e que levaram ao erro.

Linguagem discursiva: a passagem do Português escrito e da Libras para o registro algébrico, na questão 3, foi satisfatória. Apesar do número satisfatório na conversão das linguagens discursivas, nenhum aluno obteve a resposta coerente, conforme a condição estabelecida no problema (... sabendo que a idade é a maior possível). Conforme revisão da literatura, os surdos têm dificuldades em interpretar situações complexas e não é suficiente o reconhecimento verbal de um enunciado, o que impede que alunos reconheçam a variabilidade de um processo que está sendo pedido (GIMÉNEZ, 2004). 
Questões 4 e 5 - Atividade de conversão.

4. Descreva, na linguagem algébrica, os pontos descritos em cada item e associe ao gráfico que o representa.

(a) Conjunto dos pontos que têm uma ordenada positiva

(b) Conjunto dos pontos cuja ordenada é negativa e abscissa inferior a - 1

(c) Conjunto dos pontos internos à circunferência de raio 3

(d) Conjunto dos pontos cuja ordenada é oposta à abscissa

(e) Conjunto dos pontos cuja ordenada é superior à abscissa

(f) Conjunto dos pontos cuja abscissa e ordenada são de mesmo sinal

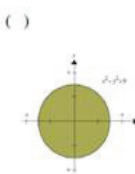

( )

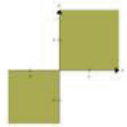

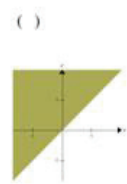

( )

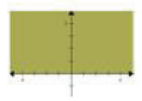

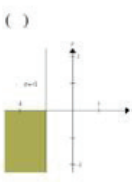

( )

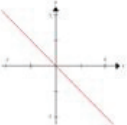

5. Para cada item, hachureie o conjunto de pontos que satisfazem a expressão algébrica dada, e descreva na linguagem natural (Libras e Português).
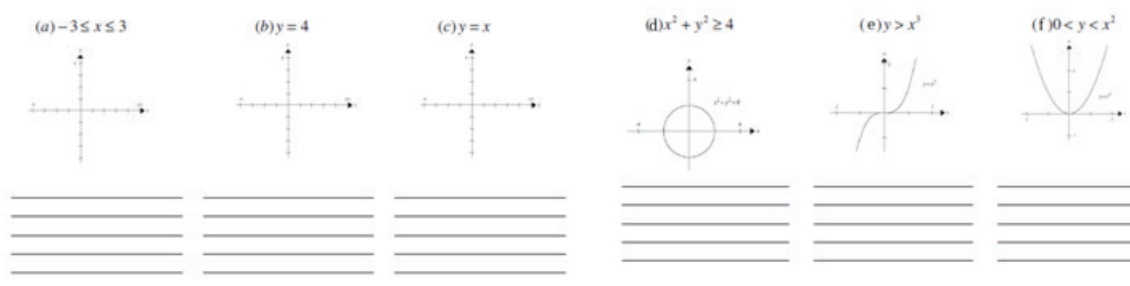

Linguagem algébrica: apenas nos itens 4 (a) e 4 (b), todos os alunos realizaram a conversão do Português escrito para a linguagem algébrica. Isso só foi possível após os alunos terem primeiro realizado a articulação com o registro gráfico. A discriminação das variáveis visuais pertinentes à representação gráfica possibilitou a conversão de algumas unidades simbólicas congruentes à representação algébrica. 
Veja a resolução do aluno A3:
(a) Conjunto dos pontos que têm uma ordenada positiva $\quad y>0$
(b) Conjunto dos pontos cuja ordenada é negativa e abscissa inferior a $-1 \quad y<0<x<-1$
(c) Conjunto dos pontos internos à circunferência de raio 3 $<-3$
(d) Conjunto dos pontos cuja ordenada é oposta à abscissa $y,-x$
(e) Conjunto dos pontos cuja ordenada é superior à abscissa $y>x$
(f) Conjunto dos pontos cuja abscissa e ordenada são de mesmo sinal $y_{+}-y^{2} / x_{+}-x$

Figura 4: representações algébricas da questão 4 realizada pelo aluno A3.

Fonte: arquivo dos autores

Para os outros itens, por falta de uma correspondência semântica - não atendendo assim ao primeiro critério de congruência - as conversões não foram realizadas. Esse fato mostra a necessidade de uma "organização de situações de aprendizagem centradas sobre a coordenação de registros" (DUVAL, 2009, p. 102), que consiste em fazer variar um só fator de cada vez, enquanto os outros são todos mantidos imutáveis.

Linguagem gráfica: todos os alunos converteram para o registro gráfico a maioria das inequações representadas no Português escrito da Questão 4 e na linguagem algébrica da Questão 5. É importante destacar que a conversão, a partir do registro algébrico, Questão 5, foi satisfatória apenas para as inequações. O mesmo não ocorreu com as equações, conforme a figura 5 , com as representações gráficas da equação "y=4", realizadas pelos alunos separadamente (Fig. 5).

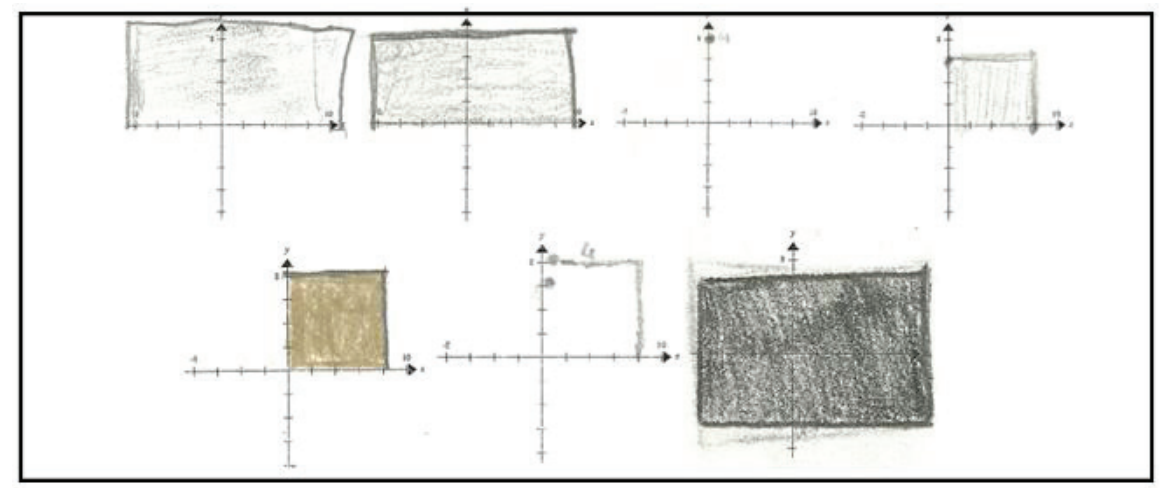

Figura 5: representações gráficas da equação y=4 realizada pelos alunos.

Fonte: arquivo dos autores

Para a maioria desses alunos surdos, as unidades visuais de uma equação são as mesmas utilizadas para as inequações. Não existe uma distinção entre inequações e equações no registro gráfico. O olhar dos surdos, com uma língua visual/motora, apresenta funções associadas à gramática espacial, num espaço tridimensional; por isso, decompô-las em dimensões menores requer um olhar mais atento. 
Linguagem discursiva: na questão 4, não houve a conversão do Português escrito e da Libras para a linguagem algébrica; parece contraditório esse resultado em relação à questão 3 , em que todos os alunos foram capazes de modelar o problema proposto para a representação algébrica. A linguagem discursiva da questão 3 apresenta variáveis linguísticas e cognitivas distintas da questão 4 , fora de um contexto. Para Duval (2009, p. 109), as variações de enunciados, em relação às eventuais mudanças da situação e até mesmo de mudanças sintáticas, correspondem a variações cognitivas, que neste caso influenciaram nos resultados diferenciados para as duas questões.

Na questão 5, o manejo e a manipulação do desconhecido fizeram com que eles utilizassem uma linguagem nova, sem significados, na passagem da linguagem algébrica para o Português escrito e até mesma a gráfica (Alunos Al e A4 - Fig. 6). Para esses alunos, a comunicação de uma linguagem algébrica se apresenta estranha, diferente e puramente simbólica; eles a representaram, no Português escrito, com palavras sem significados.

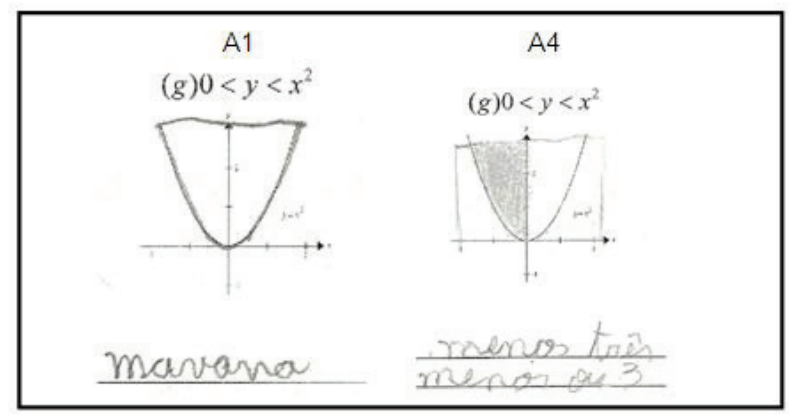

Figura 6: conversão realizada pelos alunos Al e A4 na questão 5.

Fonte: arquivo dos autores

Ao traduzirem para a Libras cada item, todos os alunos utilizaram as unidades simbólicas a partir do registro algébrico, com pequenas variações dos sinais. Observam-se, na figura 7, as três representações, em Libras, utilizadas para o sinal de "”", ao descreverem a inequação y 


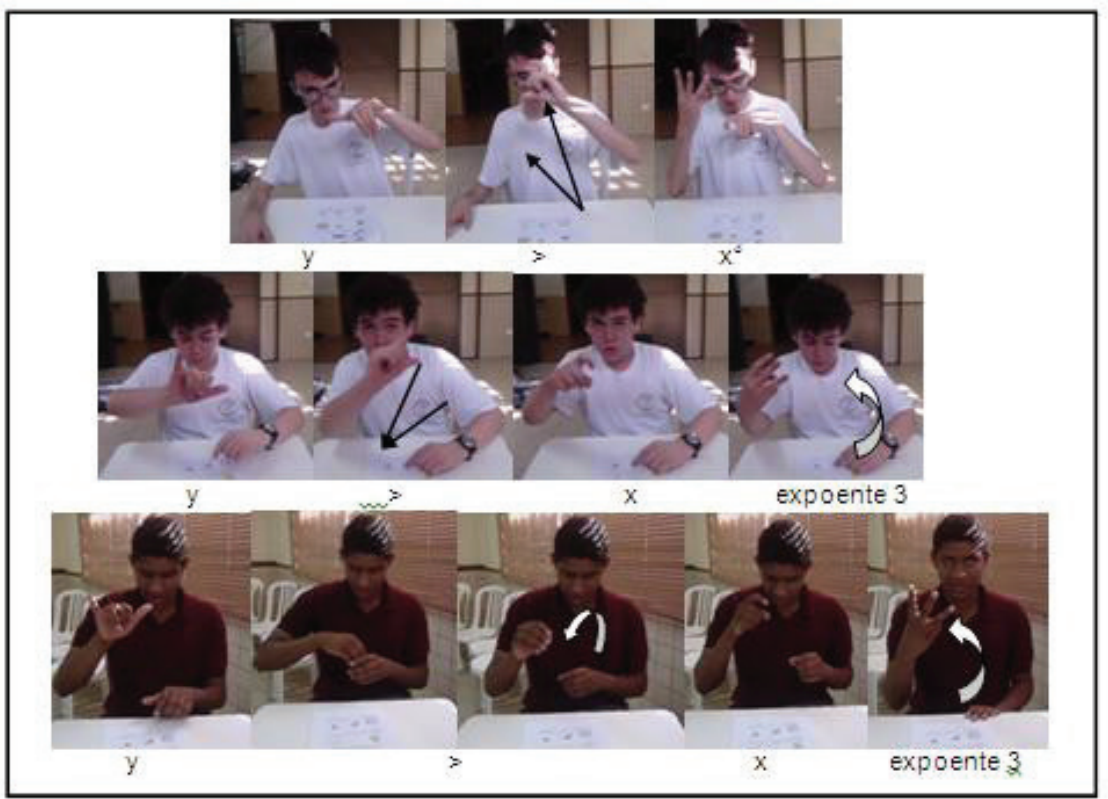

Figura 7: tradução em Libras da inequação y = x3 realizada pelos alunos A5, A3 e A6.

Fonte: arquivo dos autores

É possível perceber outras diferenças das unidades significantes entre esses três alunos. O primeiro aluno representou a potência $\times 3$ com a justaposição das mãos, uma mão para a letra x e a outra para a potência, com o movimento apenas do x (no alfabeto manual). Os outros dois alunos, no entanto, representaram essa potência com uma só mão, primeiro a letra x (no alfabeto manual), depois com o movimento de baixo para cima, para representar o expoente 3.

É muito comum, em Libras, fornecer exemplos, conforme constatado com dois alunos que utilizaram, para isso, as unidades visuais do registro gráfico. Observe o mesmo aluno A3 que, na figura anterior, traduziu para Libras a inequação $y=x 3$, com as unidades simbólicas do registro algébrico, e, em seguida (Fig. 8), fornece um exemplo para essa inequação, com as unidades visuais do registro gráfico. Para exemplificar essa inequação, ele primeiro descreveu o gráfico, com um olhar atento ao representar o seu traçado, para depois expressar a superioridade do y, no lugar do sinal de maior. Nesses exemplos, eles incluíram o $5^{\circ}$ parâmetro, das expressões faciais, muito utilizado em Libras. Em outros itens, esses mesmos alunos descreveram inclusive os pontos que faziam parte da região hachurada. 


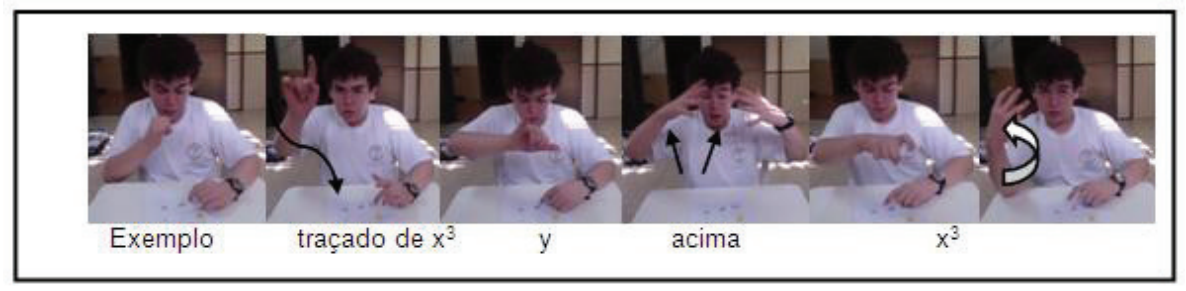

Figura 8: exemplo em Libras da inequação $\mathrm{y}=\mathrm{x} 3$ realizada pelo aluno A3.

Fonte: arquivo dos autores

O que queremos enfatizar, com isso, são vantagens que a Libras tem em relação às línguas orais e que muitas vezes não são exploradas. Os alunos apresentaram um grau de liberdade maior ao traduzirem para Libras, isto é, os alunos não ficaram presos a um único registro; a Libras, por ser uma língua visual/motora, permitiu utilizar tanto as unidades visuais, do registro gráfico, quanto as simbólicas, do registro algébrico, para traduzir as expressões algébricas na língua de sinais.

Machado (2011) explica que "[...] por decorrência de sua natureza linguística, a realização de um sinal pode ser motivada pelas características da realidade a que se refere, mas isso não é uma regra" (p. 51). Não significa que devemos pensar que todos os sinais utilizados pelos surdos para representar uma expressão algébrica são o gráfico dessa expressão. Os sinais icônicos da Libras, "que fazem alusão à imagem do seu significado" (p. 5l), assim como uma foto reproduz a imagem do referente, da pessoa ou da coisa fotografada, não são regras para os alunos surdos. Machado (2011) aclara: "[...] A grande maioria dos sinais da Libras são arbitrários, não mantendo relação de semelhança alguma com seu referente" (p.51), ou "[...] com o dado da realidade que representam" (p.52). No entanto, para os alunos pesquisados entenderem o significado das expressões algébricas tinham que necessariamente passarem pela representação gráfica, ou seja, representarem com os sinais icônicos referentes à imagem dessas expressões.

\section{Considerações finais}

Com os resultados apresentados no diagnóstico, inferimos que os alunos surdos foram capazes de representar situações matemáticas além do esperado, ao utilizarem a Libras, mesmo com o léxico reduzido. A partir dos cinco parâmetros que compõe a Libras, as traduções e os registros de representação matemática abrangeram muitas variações, por exemplo, com uma simples troca de movimento (M) ou ponto de articulação (PA). Isso favoreceu o processo cognitivo dos alunos surdos, ao trabalharem com um grau de liberdade maior durante as atividades de conversão.

O significado das expressões algébricas era alcançado pelos alunos, na maioria das vezes, ao traduzirem para Libras juntamente com a conexão entre as unidades significantes pertinentes do registro gráfico. Essas conexões, segundo Duval (2009), não são simples e o aluno, para realizá-las, deve ter claro o que significa cada componente em cada registro. Inferimos, com isso, que os alunos obtiveram, não só clareza 
do significado de cada componente em cada registro, como também a possibilidade de utilizarem, por meio da Libras, as representações gráficas durante o processo cognitivo nas atividades de conversão do registro algébrico para a Libras e/ou para o Português escrito.

A conversão contrária, também, foi favorecida com a utilização da Libras, por intermédio da representação gráfica. Para escreverem uma expressão algébrica, a partir da leitura do Português escrito ou da Libras, os alunos surdos se apoiavam na representação intermediária de um ponto em forma de par ordenado no plano cartesiano, bem como o tipo do gráfico (região ou uma linha) e a forma do gráfico (circunferência ou parábola), que, segundo Duval (201la), são as variáveis visuais gerais que mais interessam quando se estuda as representações gráficas. Inferimos, com isso, que, para esses alunos, as representações gráficas eram interiorizadas durante o processo cognitivo, quando as atividades de conversão era do Português escrito ou da Libras para as expressões algébricas e vice versa. Isso implica que, para entender algebricamente o que estava escrito em Português nas atividades, os alunos surdos estabeleciam imagens mentais, por intermédio gráfico, em correspondência com sua primeira língua, a Libras.

Concluímos, com isso, que as representações intermediárias do registro gráfico eram de fundamentais importâncias para os alunos surdos investigados, não apenas para a tradução, como também no processo cognitivo durante as atividades de conversão do registro algébrico para a Libras e/ou Português escrito e vice versa.

No entanto, para a maioria dos alunos, a atividade de tratamento algébrico prevaleceu, com a predominância de suas unidades simbólicas. Isso implicou que, o uso abusivo das expressões algébricas, por meio de suas unidades simbólicas, impediu a atividade de conversão a partir do registro gráfico, quando este era o registro de partida e não mais intermediário. As conversões dos registros não discursivos (gráficos cartesianos) para os discursivos (o Português escrito, a Libras, e a escrita algébrica) não foram realizadas em ambos os sentidos por todos os alunos. Alerta Duval (201lb, p. 118): "A conversão direta e a conversão inversa são duas tarefas cognitivas tão diferentes quanto subir ou descer um caminho íngreme na montanha".

Quando o registro de partida era o gráfico, os resultados obtidos não foram satisfatórios para esses alunos, como se fosse um conteúdo totalmente diferente aos que estavam sendo estudados quando o registro de partida era o algébrico. Os gráficos das inequações, funções ou equações não representavam os mesmos objetos que as suas representações algébricas, devido à predominância das unidades simbólicas desse último registro.

Esse fato mostrou a necessidade de se trabalhar com a conversão, em ambos os sentidos dos registros não discursivos e dos discursivos, muito importante no processo cognitivo envolvidos na matemática, conforme a teoria de Duval (2009). As implicações metodológicas desses resultados obtidos no diagnóstico foram de orientar as futuras atividades trabalhadas com esses alunos, de tal forma que, a conversão, a partir do registro gráfico, fosse realizada com sucesso. 
No que diz respeito aos conhecimentos prévios desses alunos surdos, a conversão direta foi possível apenas da linguagem algébrica para a gráfica, caso que não ocorreu com os alunos ouvintes, segundo Souza (2008). Para os ouvintes, a leitura da linguagem algébrica é realizada de forma linear, termo a termo, com influência da oralidade, assim, como acontece com a leitura e escrita do Português. Ao contrário dos ouvintes, os alunos surdos, muitas vezes, utilizavam a justaposição das mãos para a realização da leitura mesmo quando o registro era o algébrico, assemelhando-se a uma leitura do registro gráfico. A Libras, por ser de modalidade visual/motora, com informações linguísticas produzidas no espaço, pelas mãos, movimento do corpo e expressões faciais, as unidades significantes utilizadas na tradução de uma expressão algébrica, muitas vezes, correspondiam semanticamente às unidades visuais gráficas ou a justaposição das mãos para as unidades simbólicas.

Finalizamos nossas conclusões com uma advertência para o estudo da álgebra, que deve servir para todos os alunos, mas, especialmente, quando se tem um aluno surdo em sala de aula. No ensino para surdos, não devemos separar a representação algébrica dos outros registros, devido à necessidade de esses alunos realizarem uma representação a mais que as dos ouvintes. As representações mentais dos surdos dependem exclusivamente da sua língua natural, a Libras, para generalizar e abstrair as representações algébricas, tendo como representação intermediária os gráficos. Por isso, os alunos surdos devem trabalhar com as vantagens que a Libras lhes oferecem, desvinculando-se do uso excessivo dos algoritmos, de representações exclusivamente simbólicas e, principalmente, da obrigatoriedade de se obter uma resposta apenas numérica ou da linguagem algébrica.

\section{Referências}

ALMOULOUD, S. AG. Fundamentos da didática da matemática. Curitiba: Ed. UFPR, 2007.

BRITO, L. F. Por uma gramática de língua de sinais. Rio de Janeiro: Tempo Brasileiro, 1995.

DUVAL, R. Semiósis e pensamento humano: registro semiótico e aprendizagens intelectuais. Tradução: Lênio Fernandes Levy e Marisa Rosâni Abreu da Silveira. São Paulo: Editora Livraria da Física, 2009.

Gráficos e equações: a articulação de dois registros (Representation, vision and visualization: cogni-

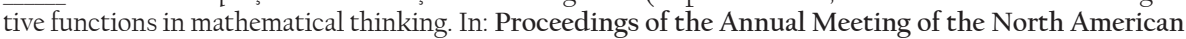
Chapter of the International Group for the Psychology of Mathematics Education - 21st, Cuernavaca, Morelos, Mexico, October 23 - 26, 1999. Tradução: Méricles Thadeu Moretti, REVEMAT, Florianópolis (SC), v. 6, n. 2, p. 96-112, 2011a.

Ver e ensinar a Matemática de outra forma: entrar no modo matemático de pensar os registros de representações semióticas. São Paulo: PROEM, 201lb.

FELIPE, T.A. Libras em contexto: Curso Básico, Livro do Estudante, 8ª edição. Rio de Janeiro: WalPint Gráfica e Editora, 2007.

GIMÉNEZ, J. et al. Evaluacion reguladora y apoyo geometrico al alumnado deficiente auditivo en aulas inclusivas en la eso. Un estudio de caso: Actas del VIII Simposio de la SEIEM (Sociedad Española de Investigación em Educación Matemática), set. 2004.

GOLDFELD, M. A criança surda. Linguagem e cognição numa perspectiva sóciointeracionista. São Paulo: Plexus, 2002.

KARNOPP, L. B. ; QUADROS, R. M. Língua de Sinais Brasileira. Rio Grande do Sul: Artmed, la ed., 2004.

LEITE, M. D., BORBA, R. E. S. R. , GOMES, A. S. O Papel das Representações Simbólicas no Design de Software Educativo numa Proposta Inclusiva, Anais do $2^{\circ}$ SIPEMAT - Simpósio Internacional de Pesquisa em Educação Matemática, 2008. 
LOPES, M. C. Surdez \& Educação. Belo Horizonte: Autêntica, 2007.

MACHADO, F. F. Língua Brasileira de Sinais (Libras). Ponta Grossa: UEPG;NUTEAD, 2011.

NOGUEIRA, C. M. I., ZANQUETTA, M. E. M. T. Surdez, bilingüismo e o ensino tradicional de Matemática: uma avaliação piagetiana, ZETETIKÉ - Cempem - FE - Unicamp - v. 16 - n. 30 - jul./dez. - 2008.

PAIVA, M. Matemática: volume único - 2. Ed., São Paulo: Moderna, 2003.

PIMENTA, N.; QUADROS, R.M. Curso de LIBRAS 1, Iniciante, Coleção Curso de LIBRAS, $2^{a}$ ed.(DVD), Rio de Janeiro, LSB vídeo, 2007.

QUADROS, R. M. Educação de surdos. Rio Grande do Sul: Artmed, la ed., 1997.

Língua de sinais. Rio Grande do Sul: Artmed, 2004.

Estudos surdos I. Rio de Janeiro : Arara Azul, 2006.

QUADROS, R. M. ; CRUZ, C. R. Língua de sinais : Instrumentos de avaliação, Rio Grande do Sul: Artmed, 2011

RAMOS, C. R. LIBRAS: A Língua de Sinais dos Surdos Brasileiros. Rio de Janeiro: Editora Arara Azul Ltda. Disponível em: 〈www.editor-arara-azul.com.br〉. Acesso em set. 2012.

SACKS, O. Vendo vozes: uma jornada pelo mundo dos surdos. Rio de Janeiro: Imago, 1998.

SKLIAR, C. (Org.). A surdez: um olhar sobre as diferenças. Porto Alegre: Mediação, 1998.

SOUZA, V. H. G. O uso de vários registros na resolução de inequações Uma abordagem funcional gráfica. Tese de Doutorado, Universidade Católica de São Paulo - PUC. São Paulo, SP, Brasil, 2008.

ZARFATY, Y. ; NUNES, T. ; BRYANT, P. The Performance of Young Deaf Children in Spatial and Tempo ral Number Tasks. Journal of Deaf Studies and Deaf Education, 9(3):315-326, 2004.

\section{Notas}

${ }^{1}$ Caso não exista um dos três critérios (I. correspondência semântqica; II. univocidade semântica terminal e III. organização das unidades significantes), a não congruência de representações estará confirmada e a dificuldade de conversão aumenta (DUVAL, 2009).

${ }^{2}$ Os classificadores fazem parte tanto da língua oral, quanto da língua de sinais. "O classificador tem a função de substituir uma palavra classificando-a em uma determinada categoria. Nas línguas de sinais, os classificadores desempenham uma função descritiva podendo detalhar som, tamanho, textura, paladar, tato, cheiro, formas em geral de objetos inanimados e seres animados" (PIMENTA e QUADROS, 2007, p. 71)

* Parte deste artigo teve sua publicação nos Anais do XI Encontro Paranaense de Educação Matemática - XI EPREM, Apucarana - PR, set/2011.

\section{Correspondência}

Clélia Maria Ignatius Nogueira - Universidade Estadual de Maringá, Centro de Ciências Exatas, Departamento de Matemática. Avenida Colombo, 5790, Universidade, CEP: 87020900 - Maringá, Paraná - Brasil.

E-mail: stfrizzarini@hotmail.com - voclelia@gmail.com

Recebido em 21 de abril de 2013

Aprovado em 12 de novembro de 2013 
